\title{
㹦art 牙trot.
}

\section{ORIGINAL COMMUNICATIONS. \\ Article I.-On the Construction of Hospitals. By Dr Watson Wemyss, F.R.C.S.E., etc.}

THE following lecture on the Construction of Hospitals for the Sick and Hurt, delivered at the Conversazione of the Royal College of Surgeons, on the evening of the 17th of February, by Dr Watson Wemyss, F.R.C.S.E., formerly a practitioner in Edinburgh and one of the Surgeons of the Royal Infirmary, but now retired from active practice, will be read with interest, as it takes a comprehensive view of the whole subject, and particularly as it relates specially to the medical profession.

\section{Mr President and Gentlemen,}

I have undertaken to lay before you this evening some remarks on the construction of hospitals for the sick and hurt,-comprehending in this short phrase (of sick and hurt) the cases of disease and injury, which, by conventional usage, are distributed into the medical and surgical wards of a general hospital.

I. At a time when there is an increasing demand for the erection of hospitals and other large buildings for the care of the sick, the hurt, the insane, and the destitute, as also for the education of youth, and the amusement of the people, the proper construction of such buildings is both important and interesting; and it becomes a matter of special concern that these should be formed and arranged, not only in the best manner for their several destined purposes, but, from the increasing wants of the people, and the many new requirements which science and art have shown to be necessary for the health, comfort, and benefit of their inmates, as well as from late disclosures, pointing out the defects and danger of such buildings, their construction and internal arrangements demand more particular attention than has hitherto been bestowed upon them.

In all civilized countries there are hospitals for the sick and hurt, and their construction has engaged the particular attention of those who, from their position in society, were required to conduct their management, and also of the medical men who had charge of the patients admitted into them. But it has been from the experience and observation of the medical men that a knowledge of the influence, arising from their construction, upon the health of their

voL. xv.- - No. $x$. 
inhabitants has been acquired. This has led to many improvements in their form, construction, and internal arrangements.

The remarks I have to lay before you relate chiefly to general hospitals for medical and surgical cases. 'They are derived from theory and experience combined, not of myself only, but from a review of what has been done by others also, over a very wide field of observation. [Allusion was here made to the enlarged plans of several of the most celebrated hospitals, prepared and hung up for the better illustration of the subject.]

I may also add, that my remarks will be entirely of a general nature, as they are intended to show the general principles upon which hospitals should be constructed, but without reference to any particular place.

I purpose to describe to you shortly the different forms of hospitals which have been erected in this and other countries, and to explain the advantages and disadvantages which seem to belong to their construction and internal arrangements. But before doing so, I must take leave to make a few general remarks on the principal objects and requirements now established as necessary in the construction of an hospital.

\section{II.-Of Plans for Hospitals.}

Experience, as well as medical science, teaches us that the health and lives of those confined in hospitals depend much, not only on the situation in which they are placed, but also on the size and construction of these buildings. Hence the interest which medical men (including physicians, surgeons, and general practitioners) are called upon to take in the selection of a site, and in the adjustment of the plans prepared for hospitals. And hence, also, the necessity for the plans being arranged by the combined experience and skill of medical men and architects. The former specify what is required, as regards the position, size, form, and internal arrangements which are necessary for the efficiency of the hospital; the latter have to devise the best and most economical manner for having these carried irito effect, and to get them executed. In doing this, the architect has abundant opportunity to exercise his ingenuity, taste, and skill, in constructing and ornamenting buildings destined to fulfil the most noble purposes. In these special departments of the architect, I may take upon me to say, neither physicians nor surgeons will interfere.

'The instructions to the architect, therefore, should be given at the commencement by the medical men. If otherwise, how is the architect to proceed? He may prepare plans according to his own knowledge of the subject; but of these the doctors may disapprove, and hence an unnecessary, unpleasant, and unseemly contest is created between the doctors and the architect, perhaps ending at last, as in too many cases it has done, in an imperfect building being produced, giving little or no satisfaction. 
In consequence of the advice of medical men having been either ignored or only partially acted upon, many of our large hospitals and asylums have not been so constructed as to be most suitable for their purposes and the health of their occupants, thus occasioning not only disappointment, but great additional cost for subsequent alterations, which too frequently have only lessened the evils experienced.

But surely the medical profession should know the best form of an hospital, and the best size and arrangement of its wards, for the health of the patients, and such other arrangements as are most suitable and convenient for the physicians, surgeons, their assistants, and other officials of the institution. And surely those who have laboured, and who are still to carry on their important work in the hospital, are, from experience, the best judges of what is needful, most beneficial, and most convenient for all concerned.

Hence it is, that neither by the architect alone, nor by a medical man, can a proper plan for an hospital be formed; but only by the combined experience and skill of both. And much labour and trouble would be saved, by the needful instructions to the architect being given at first by the doctors.

\section{III.-Of the Principles upon which Hospitals should be constructed.}

From what has been said, it therefore becomes a very important matter for the public, that those well-ascertained, definite, and established principles which have been acquired by experience, and have obtained the general approval of the medical profession, and upon which hospitals should be constructed, should be known and kept in view by those who are employed in preparing designs and plans for them. And it is no less important, also, for the medical men, who have the weighty responsibility of the proper care and treatment of the patients admitted into them, to see that these principles are properly carried into effect.

(1.) Of the Site for an Hospital. - The first of these principles to which I shall allude is the selection of a site for an hospital. This should be an airy, dry, and somewhat elevated situation, well exposed to receive the rays of the sun, and sheltered from the most hurtful winds which prevail. It should be well supplied with good water, and possess proper and efficient drainage. And it should not only be of sufficient extent for the buildings required, but also for airing-grounds for convalescent patients, as this would also secure more open space for the buildings.

(2.) Separate Buildings for the Medical and Surgical Departments of a general hospital, distinct from each other, are now considered, if not absolutely necessary, at least to be a great improvement in its arrangements. The cases of the various diseases and injury which present themselves for admission into an hospital, being easily separated and assigned to the physician and surgeon respectively, with sufficient accuracy for treatment and clinical instruction, it is of 
importance that the medical and surgical wards should be in separate buildings. The great advantages to be derived from this arrangement are-first, that the number of patients under one roof will be lessened; and, second, that the extension of contagious diseases to patients under surgical treatment for injuries and other local complaints may be prevented.

(3.) Separate Divisions for Male and Female Patients.-It is scarcely necessary to say that each of the two departments of which I have spoken have again to be divided for the separation of the sexes. Hence a general hospital, consisting of medical and surgical departments, requires two sides or divisions, one for the male, the other for the female wards, thus forming four separate divisions, to which I shall afterwards have occasion to refer more particularly.

(4.) Hospitals should consist of Two Floors only.-Hospitals should not consist of more than two floors, or stories, above a basement floor. Long stairs leading up to wards higher than this are extremely inconvenient and disadvantageous in many respects, by being too distant from the apartments of the resident officials and other parts of the hospital. Besides, as the foul heated air from the lower parts of a building ascends to the higher parts, the concentrated foul air of the lower wards ascends to those above, so that by limiting the building to two floors the noxious circulation and effects of this foul air may be much lessened. Other reasons for this limitation, connected with the pavilion system, will be afterwards stated.

(5.) Size of the Wards of an Hospital.-As you all know, life and health cannot be maintained without a constant supply of fresh air, which, in confined situations, requires to be very frequently renewed, more especially in the case of sick persons confined within the wards of an hospital.

'This circumstance, therefore, constitutes one of the chief objects to be secured in its wards, and is to be accomplished-

$1 s t$, By the air space provided for each patient being at least from 1000 to 1200 cubic feet;

$2 d$, By the properly proportioned breadth, length, and height of the wards ; and,

$3 d$, By efficient means being provided for ventilation.

The form of wards may be either square or oblong; if square, their size would be very limited, because, there being no occasion for a ward being more than 26 or 28 feet in breadth, this would form the size of the ward made square.

The size and proportions of a ward are not now arbitrary, certain data founded on experience having been fixed, by general approval, for their dimensions. These data consist of the extent of air space and floor space for each bed, requiring certain proportions in the breadth, length, and height of the ward. The result is, that, as a medium, the air space for each patient should be at least 1000 or 1200 cubic feet, and the floor space for each bed about 90 square 
feet. Hence, a ward of an oblong form, having a row of beds on each side of it, and of a medium size, should be 26 feet in breadth, 15 feet in height from the floor to the ceiling, and 7 feet in length for every two beds opposite to each other. These dimensions secure for each patient 1365 cubic feet of air space, a sufficient separation of the beds, and ample room for the attendants to go about; and the total length of a ward will depend on the number of beds it is intended to contain, -7 feet of length being added to it for every two opposite beds. These dimensions cannot well be departed from, or lessened, to any considerable extent, without injurious consequences as to efficiency. ${ }^{1}$

A knowledge of the proper size for wards is important to medical men, in order that they may see that they are not too much crowded with beds. The extent of space considered necessary for each individual is a matter of importance also to the community, as showing what the size of their apartments ought to be.

(6.) Ventilation and Heating of the Wards.-The free circulation of fresh air or ventilation of the wards of an hospital being another matter of the utmost importance, requires much attention from those concerned in their construction.

There is too much reason for the opinion that, when sick or injured persons are confined together within the wards of an hospital, the contained air not only becomes vitiated or foul from respiration, but there is also a peculiar malaria engendered, which is very detrimental to the health of all within the house, unless the most ample and efficient means are provided to counteract these effects, by the constant renewal of the air contained within the wards from without. The very serious consequences produced by this malaria have formed the chief objections which have been urged against large hospitals.

To effect the complete and proper ventilation of a ward, windows are required on both sides of it, opposite to each other, and not on one side only. And the windows should be so constructed that, when required, fresh air may be admitted without injurious draughts upon the patients. Windows for hospitals have been constructed in many different ways, with ventilators and other appendages; but none seem better adapted for the ingress of fresh air and the exit of foul air, as also for easy regulation and management, than our common sash windows, made to open both above and below, and provided with some additions (as of perforated glass or zinc), to prevent direct draughts upon the patients.

In this climate the windows should not be too numerous; one window between every two beds may be considered quite sufficient.

1 The floor space and air space for each bed is easily calculated, by multiplying the length and breadth for two beds together for the floor space, and then multiplying the product of these by the height of the ceiling for the air space; by dividing the result by two will be the dimensions for each bed. 
The heating and ventilation of hospitals may be made serviceable to each other, and should, therefore, be considered together.

By attempting to effect these objects by complicated constructions and machinery, disappointment has been the general result; so that the simplest means-i.e., the proper construction and regulation of the windows and open fireplaces-have been reverted to, being found to answer best. By these means, what has been termed "natural ventilation" is secured, generally found sufficient, easily regulated, and is a saving of cost.

But when wards are very large, and in cold weather, other auxiliary means, such as stoves and hot-water pipes, may be necessary for heat and ventilation. And one of the best and safest modes of using these consists in placing them in the lobbies, passages, and corridors; and along with this, by placing louvres above the doors, and ventilators at the roof, the air of these parts may be kept pure and sweet, and being heated, may be admitted into the wards at night in cold weather with great advantage, when open windows would be unsafe.

Cases showing the injurious consequences which have been caused by the absence of open fireplaces and opposite windows in wards, and the salutary effects from these being supplied, might here be adduced, but I forbear to occupy your time with such details.

The baneful effects of the peculiar foul air of an hospital on the health of its inmates, have been termed "Hospitalism." Of these bad effects in many large hospitals, arising either from defects in their construction or management, there can be no doubt. But upon this it is not my intention to dilate, leaving this part of the subject to the much more able hands of our distinguished friend, Sir James Simpson, who has done so much to elucidate it, and who has collected and contributed so much valuable information regarding it, as to lay the profession and the public under very deep obligation; because what has been brought to light forms and places before us a beacon, warning us against a prevailing cause, which prevents the success of the best applied medical and surgical treatment, but which may be either lessened or altogether removed.

Do not suppose, however, that I have any desire or inclination to say anything in the least approaching to a general condemnation of hospitals, - a conclusion to which some have thought that the late discussions on the subject by medical men necessarily lead. The facts ascertained certainly show very clearly that much is wanted in the proper construction and management of hospitals, to render them equally healthy with the habitations of those who are obliged to resort to them, for the safety of their lives and the restoration of their health.

There is yet too much to be said, however, in favour of hospitals for the sick and hurt to prevent any discussion such as that lately carried on, from lessening public opinion in support of such institu- 
tions. But we must all hope, that the facts and observations which have disclosed many defects will have a most beneficial effect in causing great improvements and ameliorations to be made in the construction of these buildings, - the defects of which are productive of the cause of those less successful results in medical and surgical practice which have been experienced, more than anything else. In short, the evils pointed out are remediable, for they may be lessened, counteracted, or entirely removed.

I need not, I presume, recall to your attention the great and important advantages derived from hospitals for the sick and hurt, further than to say, that it is not alone the patients who resort to them, the physicians and surgeons who practise in them, or the medical students who attend them, who benefit by them-the whole community, the public in general, and the public service of the nation, equally derive important advantages by the improvement in the "healing art" acquired in these institutions; and also by their lessening the extent to which contagious diseases may spread, if those first affected are not separated and removed from their neighbours, but which, in the case of the lower orders, can only be effected by a removal to hospitals.

On the other hand, if such hospitals, so long and firmly and so deservedly established in public estimation, by the great benefits they have conferred, were to be abandoned and swept away, a very great want would soon be felt, not only by the lower orders of the community, whose claims upon them are of the most urgent nature, but also by medical practitioners and their schools, ever zealously desirous for the advancement of their profession, both as a science and as an art, which can be best cultivated in the extensive field of practice presented to them in a large general hospital.

(7.) Efficiency and Economy in the construction of hospitals require particular attention from those who are concerned in forming plans for them. But efficiency is the first object. Economy is only secondary to it. The remarks I have already made relate chiefly to the efficiency of an hospital as depending on its construction. Economy can only be practised within certain limits, because experience has shown, that the wards of an hospital and the accessories now required, demand very extensive accommodation, which cannot be much lessened without injury to its efficiency.

\section{IV.-Of the different forms of Hospitals.}

I come now to describe shortly the different forms of hospitals which have been erected in this and other countries, and to point out what appear to be the advantages and disadvantages of each. We may then be able to arrive at the conclusion as to the best form of a general hospital for the sick and hurt.

It will simplify my description of hospitals very much to classify them according to their internal construction.

Upon a wide and general survey, we find that all hospitals have 
been constructed on one or other of two different systems-the pavilion and corridor systems, or upon a combination of these two. I shall, therefore, arrange them into three classes.

(1.) Class first.-The Pavilion System.-In the first class I include all those hospitals consisting of a single line or block of building, or of several blocks connected together, having their wards occupying the whole breadth of the building. Wards of this form have been called "pavilion wards," or those constructed in the pavilion form; and the hospitals by which they are composed, as constructed on the pavilion system. [Sketches of pavilion wards and pavilion hospitals were here referred to.]

Each of these pavilions forms a separate hospital, possessing all the necessary requirements,-namely, wards of proper size and proportions, windows on both of their opposite sides, open fireplaces, and other accessories suitably connected with it; and the whole pavilion is capable of being shut off and isolated from the general building or hospital of which it forms a part.

This pavilion form of wards being now most generally approved of, many of the recently erected hospitals present to us examples of this pavilion system, including, in their details, all modern improvements.

As an example of a small county hospital constructed on this system, that of the Surrey County Hospital, Guildford (erected in memoriam of the late Prince Consort), is very complete in all its arrangements and details. But as it consists of only one ward for 26 male patients, and another for females, it can only be employed either as a medical or as a surgical hospital-the placing together of medical and surgical cases in the same ward being highly dangerous and improper. No county hospital, therefore, should consist of less than four wards, in order that the medical and surgical cases may be kept separate from each other.

The large pavilion hospitals, about which so much has been said of late, are constructed on a much grander scale, and are different in the arrangements of their pavilions and wards. They are ranged and connected together by pa:sages or corridors at their lower floors, so as to form one large general hospital.

In form and principle the wards individually are the same in these as in the smaller hospitals. But when a number of pavilions form one large general hospital, they may be connected and arranged in several different ways, as those of the Hospital Lariboisière of Paris, Herbert Hospital, Woolwich, the new St Thomas's Hospital, London, and others. ${ }^{1}$. The first of these is composed of ten pavilions, five of them being ranged on each side of a large court; $\mathrm{St}$ Thomas's Hospital consists of seven pavilions ranged in one row. Each pavilion of these hospitals, in which there are wards for patients, is of three floors in height above a basement floor, and, consequently, they are about 70 feet in height. Hence, when such ${ }^{1}$ See Appendix, No. III. 
pavilions are placed near to each other, as at a distance of only from 60 to 100 feet, they may act as a screen to one another, by preventing the free circulation of fresh air around them, and the sun's rays from falling upon them; and, besides, the intervening spaces or courts must be damp and ill-aired. I may add, that the pavilion form of wards is not new; but the arrangement of them into one large hospital is of modern date. ${ }^{1}$ [Here enlarged plans were referred to as illustrating these remarks.]

Every ward in the pavilions of St Thomas's Hospital is intended to be as complete and perfect as possible in every respect. ${ }^{2}$ [Here an enlarged plan of one of these was referred to.] The main features of these pavilions and wards are:-

1. Complete separation from each other.

2. Each pavilion forms an hospital of itself, which may be shut off and isolated from the other parts of the hospital when required.

3 . The wards have windows on both sides and open fireplaces.

4. Their form is most favourable for the free circulation of air and abundance of light.

5. They have the necessary accessories attached to them, though apart from the wards. These consist of consulting rooms, nurses' rooms, a ward kitchen, a small separation ward, lavatories, baths, and water-closets.

6 . From the manner of these arrangements, the wards are very complete and easily superintended.

Objections. - Several objections have been made to this pavilion form of hospitals. Two of these only seem to call for any remark.

$1 s t$, It has been objected to as being more expensive than one large block of building. No doubt this must be so to a considerable extent; but, if possessed of superiority and advantages over other forms, are these not worth some greater cost?

$2 d$, It has been alleged that this isolated and exposed form of wards is unsuited to the coldness of this climate, and would require additional means for heating them. This objection, however, has not been felt or complained of where wards of this form have long been in operation, as those in the old part of our Edinburgh Infirmary. In warm climates this objection could have no weight.

General Remarks.- If these pavilion hospitals, composed of wards, theoretically so excellent and complete, do not answer expectations as to their salubrity, there must be some fault existing as to the situation and relative position of the pavilions to each other, or in the regulation of their details when in operation. I

1 The Hospital Lariboisière was built to contain 600 patients, at a cost (it is said) of $£ 400,000$. Each ward, for 22 beds, is 115 feet long, 26 feet broad, and 15 feet in height, by which each patient will have 1900 cubic feet of air space.

2 The new St Thomas's Hospital, London, is to contain 588 patients, at an estimated cost of $£ 360,000$. Each ward, for 28 beds, is 120 feet long, 28 feet broad, and 15 feet in height, by which each patient will have 1800 cubic feet of air space.

vor. xv. - No. x. 
must add, however, that for certain reasons they are still considered to be on their trial, and will require some longer time and experience to test their merits.

But the most important question regarding them at present appears to me to consist of the proper and best arrangement of the pavilion blocks of which they are formed. In order to secure the benefit of the free circulation of air and sunshine, their position and distance from each other seem to me to be matters of the greatest importance; for it is always to be kept in view, that the best form of an hospital is that which secures most light and sunshine, fresh air and heat, to its inhabitants.

The improvements yet to be made on these hospitals, therefore, I am disposed to think, will chiefly consist in the most suitable and advantageous arrangement of their pavilions, and in their height being limited to one or two floors.

(2.) Class second.- -Hospitals constructed on the Corridor Sys.TEM.-These form the second class of hospitals, to which I now beg to direct your attention.

These hospitals are so constructed that, in place of their wards occupying the whole breadth of the building, they form only one side of it, having on the other side a passage or corridor from which they enter. In some of these hospitals the corridor occupies only one side of the building, as in the great General Hospital of Hamburg; in others, the corridor occupies the centre of the building, as in several hospitals which could be named, there being wards on each side of it. This last form or arrangement of an hospital appears to be the most objectionable of all. The wards, having windows only on one side of them, cannot have that free ventilation which is necessary, and the corridors in their centre can neither possess that sufficient light nor fresh air which they ought to have. In these wards, the invigorating currents of fresh air, which pass through wards having windows on opposite sides of them, cannot be obtained, the foul air stagnates, the wards get unhealthy, and alterations are required to improve them, such as the removal of partitions, or making apertures through them for the admission of fresh air; but these alterations are seldom satisfactory, and have been found only to lessen the evils and disadvantages in these hospipitals caused by their construction. This form, or corridor system of hospitals, is now generally considered to be so objectionable that the pavilion system is preferred. I regret to add, that I consider it beyond dispute that the corridor hospitals are the most unhealthy, notwithstanding extra appliances, care, and attention for the health of their inmates; but if small wards are considered best, corridor hospitals admit of these, as in the Hamburg Hospital. Most of the lunatic asylums in this country are on this system.

(3.) Class third.-Hospitals constructed on the Pavilion and Corridor Systems combined form a third class, into which I have arranged them. St George's Hospital, London, is an example of 
this form of an hospital. In this the central part has the form of a corridor hospital, with wards on both sides of the corridor, while the wings attached to it consist of wards of a pavilion form. [Enlarged plans of the Hamburg and St George's Hospitals were here referred to.] Many existing hospitals of old date have been constructed in this form, which, in several respects, is simple and good; but several of their wards must be defective in the means of ventilation required. Nevertheless, many of them have proved very efficient in practice, and still continue to do so.

Of buildings surrounding a central court.- To the different forms of hospitals which I have described, I have to add that hospital buildings surrounding a court or enclosure have been considered to be unfavourably situated for the circulation of fresh air around them and into their wards. But when the central court is large, the buildings not too lofty, and situated with sufficient open space outside, such an arrangement should not be objectionable.

\section{V.-Accommodation for the Officials of Hospitals.}

After all that I have said regarding the situation, form, and other arrangements of the wards of hospitals, I must remark that, although very important, these are not the only objects which require particular attention in the construction of hospitals. The "administration," or officials of different classes, who conduct their operation and management, require ample and extensive accommodation; and many accessories require the same; so that when I enumerate the chief of these, and direct your attention to the proportion of the buildings of St Thomas's Hospital, and of the Lariboisière and other hospitals, which they occupy, you cannot fail to observe their importance, and the great extent of space they necessarily occupy.

'To provide proper and suitable accommodation for the board of management; rooms for attending physicians and surgeons; apartments for the resident medical officers; a hall, library, and museum for students; waiting rooms for patients; accident rooms; theatres for lectures and operations, together with proper accommodation for the apothecary, the house steward, the matron, the nurses, and other servants of the institution; as also kitchen, laundry, storerooms, and others, it must be evident, not only that much space is required, but also much skill and attention, to place each of these adjuncts in the most convenient and appropriate position for their different occupants and purposes, which can only be done by the combined knowledge and skill of the medical and surgical practitioners and architects.

\section{VI.-Conclusion.}

Keeping in view those principles which $I$ have endeavoured to represent, as established by the experience and general opinions of the medical profession, for the proper construction of hospitals, I shall conclude by suggesting a Plan (as an example in illustration 
of the subject), by which these principles may be most advantageously combined and carried into effect. In doing so, I shall keep within those bounds which I described as the province of medical men in this matter.

Assuming that the pavilion system is to be adopted as the best, I have here sketched out a plan or diagram of the first floor of an hospital, which embraces all that is required, and what I consider an improved and less objectionable arrangement of its pavilions than that of the great hospitals I have referred to.

(a.) This diagram is intended to represent a plan for a large general hospital on the pavilion principle, for about 400 patients. ${ }^{1}$.

(b.) It consists of two distinct and separate buildings for the medical and surgical departments. These, again, are each separated into two divisions for male and female patients.

(c.) For efficiency and economy, each division consists of a double pavilion; these being after the model of those of St Thomas's Hospital.

(d.) These pavilions are intended to be of two floors only above the basement floor, and of medium size.

(e.) The pavilions are connected by corridors of only one floor in height. In connexion with these corridors also are theatres, consulting rooms, waiting rooms, and others, for the resident medical officers, apart from the wards.

$(f$.$) Each of the four double pavilions contains four wards, each$ to contain from 22 to 24 patients. $^{2}$ And they each possess the accessories required-consulting room, kitchen, small ward, etc.

(g.) Each pavilion can be isolated, or shut off, from the other parts of the hospital.

(h.) Smaller special wards, day rooms, and ophthalmic wards are intended to be added. The whole to contain 400 patients. The basement floor would be occupied by the departments of the apothecary, matron, and others.

(i.) The central court is large, being above 200 feet square, and free ventilation is assisted by the entrance openings at each side.

(j.) The pavilions are so placed, and at such a distance from each other, that they are not likely to screen each other by intercepting air and sunshine. And the corridors, being only one floor in height, cannot injuriously confine the air within the central court. The pavilions are intended to stand in a line from east to west, by which one side of them will be exposed to the south sunshine. ${ }^{3}$

General Remarks. - If the expected excellence of pavilion hospitals is proved and established, as seems most probable, I contemplate that they will cause a complete revolution in Scotland in the planning and construction of hospitals, asylums, and poorhouses; so that the example of England and other places ${ }^{4}$ may be followed, as I trust it will be, with very beneficial results. But let those who

1 See Plate I.

3 See Plate II.

${ }^{2}$ Each division will contain about 100 patients.

4 France, Algeria, America, etc. 


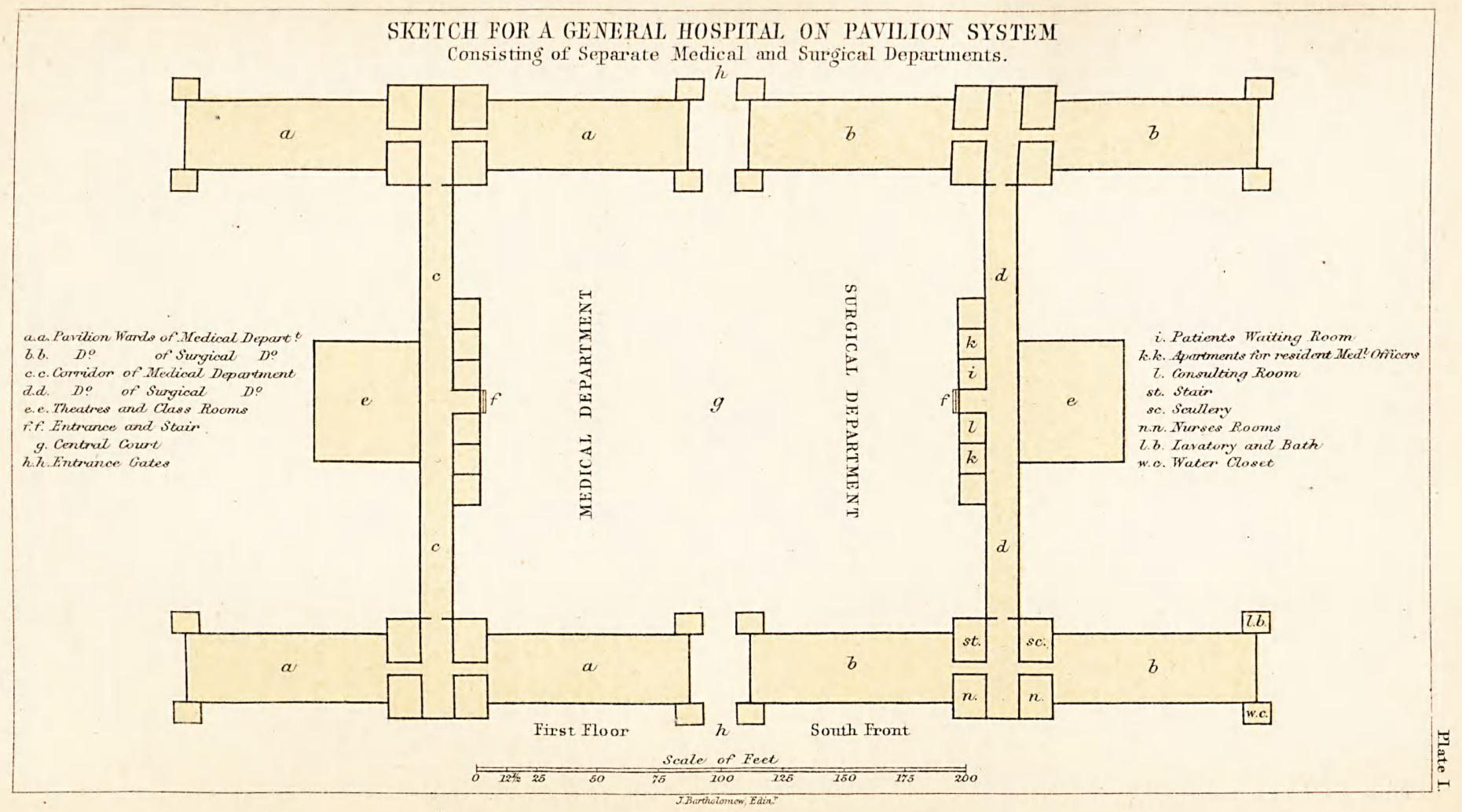


adopt this form of hospitals see to it that it has fair play-that the pavilion blocks are not too lofty-that they are placed on a proper site-that they are properly arranged, and not too close together; for if these important requisites are not judiciously fulfilled, the advantages to be derived from it may be frustrated, and not obtained to the extent expected. If the premises I have laid down are correct, any deviation from them must be wrong; and, if to a great extent, must end in a complete failure.

In the remarks I have had the honour to submit to you on the different forms of hospitals, I have avoided as much as possible to occupy your time with too many details; and have endeavoured to confine my observations to the more prominent and essential points required in the construction of these buildings, at once designed to combine efficiency, as regards the treatment of the patients,-economy as regards the public, who generously maintain these institutions,-and also as the form best adapted for medical and surgical experience, as regards the cultivation of the healing art.

A Fever hospital, a Maternity hospital, a Lock hospital, and a Lunatic hospital, should each have a separate locality, and be situated at a distance from a General hospital for the sick and hurt. Had time permitted, I might have made some additional remarks on each of these, with reference to the special construction they severally require. But I have already occupied your attention too long.

And now, if the remarks I have made for your consideration on this important subject tend, in any measure, to solve the great problem of combining and including what experience and science have shown to be desirable and necessary in the construction of hospitals for the relief of the sick and hurt-as affording the best means for the care and curative treatment of the suffering and destitute portion of our fellow-creatures-imparting to them, by its ample provisions for their welfare, confidence, hope, and encouragement amidst their troubles, giving health to the sick, sight to the blind, and making the lame to walk, and thus restoring many heads of families to their homes, to resume that parental care and support to those depending on them, of which they had been deprived by sickness or accident, and thereby, the Hospital, by the good it confers, giving the best assurance to the benevolent and generous of the community, that their charity is most beneficially and faithfully applied to the purposes intended, my object will be attained, and my most anxious desire amply gratified.

\section{Appendix, No. I., Plate II.}

Sunshine and Light.-There is a prevailing idea among those who are concerned in the construction of hospitals, that, by placing the pavilions with their long axis north and south, their wards will receive more sunshine into them, than if placed in the opposite direction, from east to west. This I consider to be a great mistake, as the accompanying diagram plainly shows. (Plate II.) 
Figure 1.-A represents a pavilion within a circle indicating the position of the sun at different hours of the day, as marked upon it. The narrow ends of this pavilion are placed north and south. At 6 o'clock in the morning, if the sun is up, its rays strike directly on the long side of the pavilion. But from that hour till 12 o'clock, the rays fall less and less directly, and more and more obliquely, upon it, till at length they strike upon the south end of it at that hour, without getting any admittance. After 12 o'clock, the sun's rays again shine upon the side of the pavilion, obliquely at first, but they gradually do so more and more directly, till 6 o'clock.

In this progress of the sunshine, it is obvious that the rays abound most in the wards at 6 o'clock A.M., and become of less and less extent till mid-day, when none of them enter the wards at all; while from 9 till 3 o'clock, the entering rays are oblique and few in number.

Figure 2.-B, in the centre of the circle, represents the pavilion placed with its long axis from east to west. Here the rays of the sun are represented as falling most copiously and directly upon the side of the pavilion at 12 o'clock, when its rays are strongest. It will also be observed that the rays at 6 o'clock A.M. fall directly on the end of the pavilion, at a time when they are much less effective; but they gradually increase in directness and extent upon the side of the pavilion till 12 o'clock, when the sun's rays are strongest. They then gradually decrease as the evening advances.

When we consider, further, that when the days become short for several months in winter, and the sun only shines from 8 or 9 o'clock till 4 or 5 , the oblique rays falling upon the pavilion between these hours, as shown in Fig. 1, are not to be compared in efficiency with those more direct rays upon the side of the pavilion during these hours, as shown in Fig. 2.

It, therefore, seems to be quite a fallacy to suppose, and adopt the opinion as correct, that the pavilions would derive any greater advantage from the sun by being placed with their ends to the north and south, than if placed east and west, but rather much the contrary.

\section{Appendix, No. II.}

Ventilation.-The pavilion system for wards and hospitals is theoretically approved of by all; but in some cases, where it has been carried into practice in a very complete manner, there has been disappointment from apparent failure as to salubrity. To what is this to be ascribed? The chief cause alleged for this is the want of sufficient ventilation. There seems to have been too much dependence placed in the system of artificial ventilation employed, and expected to have been secured, by the complicated constructions and machinery introduced into the buildings. Where this has been done, it must have considerable influence; because the successful operation of such constructions requires the absence 
Plate II.

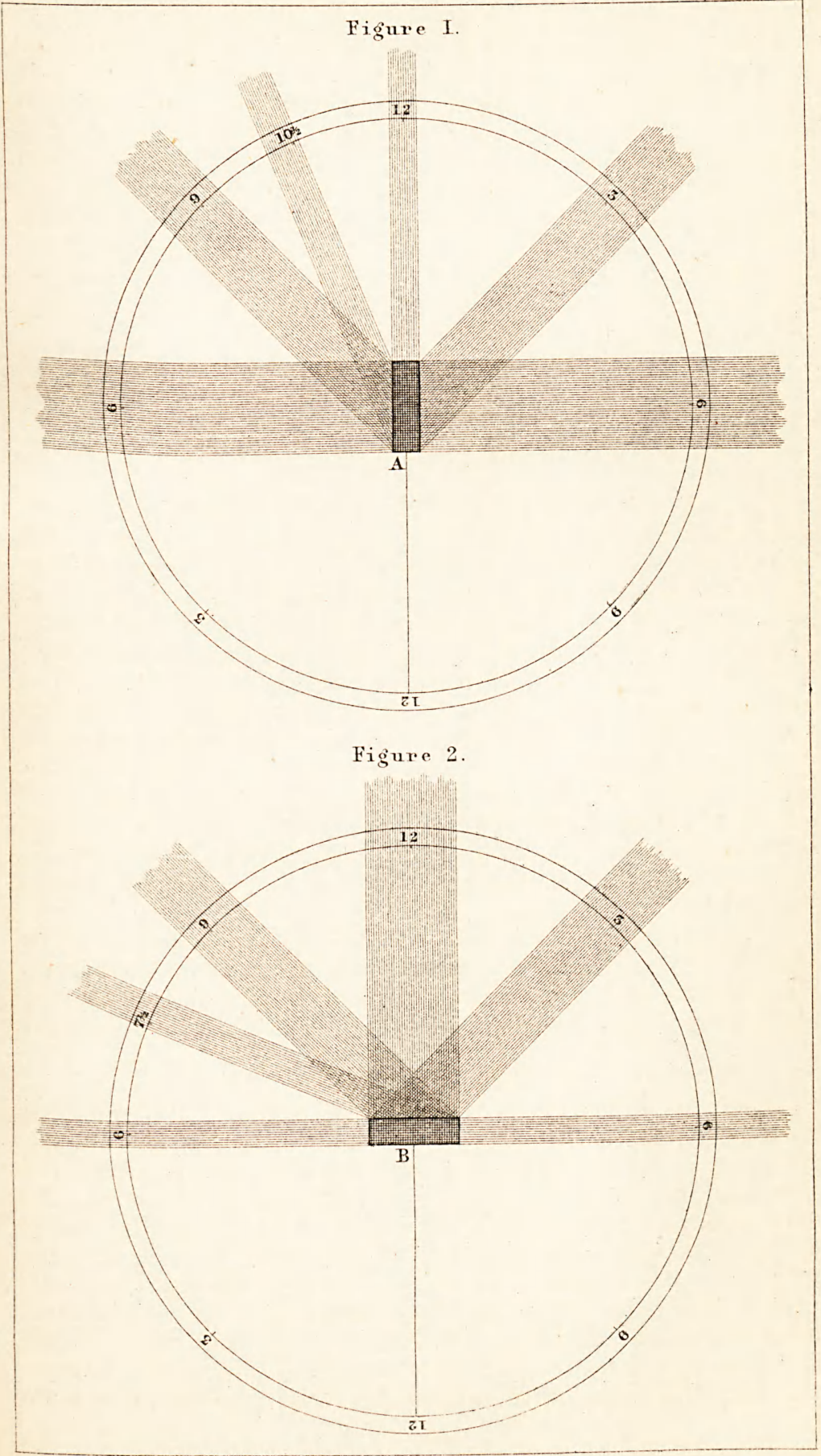


of open fires and windows. So that all natural ventilation for supplying fresh, and removing foul, air, has to be prevented; and its place supplied by heated, and probably polluted, air forced into the wards by machinery, which cannot be expected to work with regularity, or be always properly managed by attendants. Besides, such constructions are expensive to erect and maintain in operation; and general experience has shown that they are not to be relied on. The influence of this mode of ventilation, therefore, cannot fail to be detrimental and disadvantageous to the health of those confined in hospitals so constructed. Hence, artificial ventilation should not be trusted to, in preference to natural ventilation, which has these several advantages:-(1.) It always supplies pure air. (2.) It can always be established without any additional expense in the construction of an hospital. (3.) It is not expensive in operation. (4.) It is easily regulated. (5.) It seems to be that mode intended by Providence for the continued supply of fresh air to man and beast-to be used and regulated by properly-constructed buildings, and not counteracted, obstructed, prevented, or excluded, in order to be superseded by complex machinery and impure air; and, therefore, artificial means of ventilation should only be employed as auxiliaries to natural ventilation.

\section{Appendix, No. III.}

Position of Pavilions.-Another cause of defective ventilation consists in the arrangement and position of the pavilions composing large hospitals. When they are ranged close together, and parallel to each other, with too little intervening space, ${ }^{1}$ the free circulation of fresh air around them is prevented. The wind may beat strong upon the side of the pavilion opposed to it, but this one shelters and screens the others from its influence. The foul air, also, of one pavilion may be blown into the open windows of that next to it; and the stagnant, and probably damp, air of the intervening court may find its way into the wards. These are evils which may be prevented by the pavilions being placed in long straight lines, at a sufficient distance from each other, as in the plan proposed in the preceding pages. These lines should be placed from east to west; for, in this position, the prevailing winds in this country would strike them on their ends, and, passing along their sides, would supply fresh air to them in a gentle manner, and thus the pavilions would be little affected by storms.

The objectionable position of the pavilions of hospitals is exemplified in that of the Herbert Hospital, Woolwich (Fig. 2, page 880), in which the pavilions consist of a basement and two ward floors above it, making the height 54 feet, and are only 64 feet apart from each other. Their extremities are also placed nearly north and south; being altogether in the most unfavourable position either for sun or air. 
DR W. WEMYSS ON THE CONSTRUCTION OF HOSPITALS. [APRIL Fig. 1.-HOSPITAL LARIBOISIÈRE, PARIS.

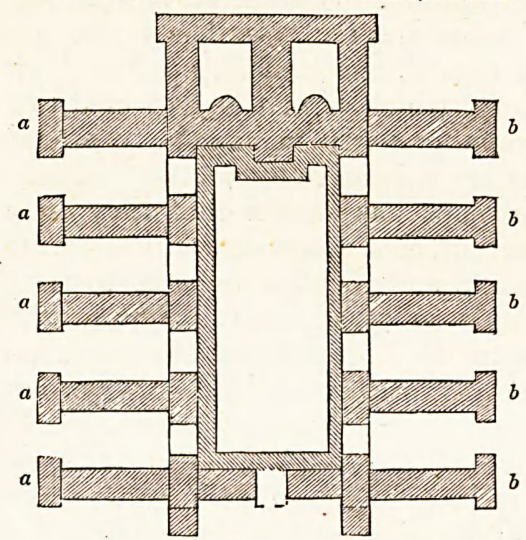

The position of the pavilions $(a, b)$ of the Lariboisière Hospital, Paris, is equally objectionable, as seen in the above figure. See page 872 .

Fig. 2.-HERBERT HOSPITAL, WOOLWICH.

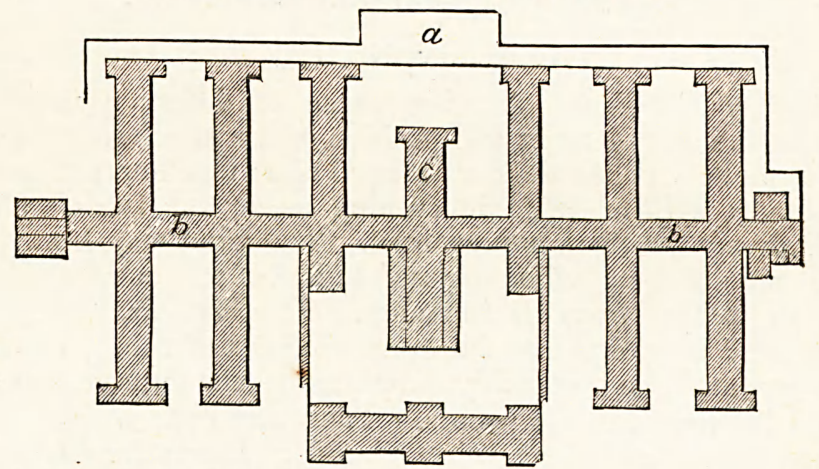

$a$, Promenade. $\quad b$, Corridor by which the pavilions are connected and entered.

In this instance the pavilions are too close together, and stand in a wrong direction, as already stated.

FIG. 3.-NEW ST THOMAS'S HOSPITAL, LONDON.

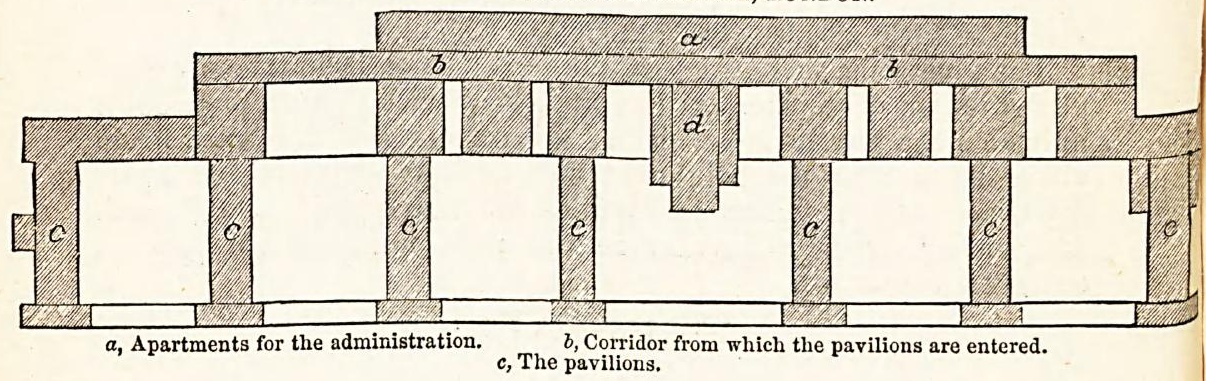


The foregoing figure, showing the position of the pavilions of the new St Thomas's Hospital, London, also illustrates the remarks above made against this arrangement.

The pavilions of this hospital are about 70 feet in height, consisting of a basement floor, three ward floors, and attics, and the distance between the pavilion blocks is only 125 feet.

Considerable disappointment has already been felt in regard to the salubrity of several of the hospitals erected in this manner; and if the above statement as to the alleged causes of this is correct, it follows that some better arrangement of the pavilions is necessary, and should be adopted; for any mistake in this matter could not easily be remedied.

Article II.-Observations on Amputation at the Hip-Joint. By Thomas Annandale, F.R.S.E., Surgeon to the Edinburgh Royal Infirmary.

Although the use of chloroform and the efficient compression of the abdominal aorta have tended to diminish the immediate risks of amputation at the hip-joint, the mortality of this operation is still very great. This mortality is principally due to the severe shock which results from the infliction of so large a wound, and the removal of so considerable a portion of the body. If the patient survives the first period of shock, the accidents, irritation, and exhaustion attendant upon the healing of the large wound also produce, in the majority of cases, a fatal result.

I think it is justifiable to consider, that the immediate shock to the system, caused during the infliction of this and other large wounds, is much diminished, if not prevented, by having the patient completely anæsthetized; and there can be no doubt also that, with the assistance of the abdominal clamp, amputation at the hip-joint may be performed, with the loss of only two or three ounces of blood." ${ }^{1}$ Surgeon S. U. Gross ${ }^{2}$ says, "The ratio of mortality in all hip-joint amputations has certainly diminished since the introduction of chloroform, and I think we possess in it a powerful agent against shock, which in former days was so fruitful a source of mortality." He says, further, "Hæmorrhage, as a source of danger, is now robbed of its terrors by the employment of the abdominal tourniquet for compressing the aor:a." $\mathrm{Mr}$ Gamgee, ${ }^{3}$ in his interesting account of a case of amputation at the hip-joint, remarks-" But so effectual was the aortic tourniquet that

1 The total loss of blood may be still further diminished in many cases by carefully bandaging the limb, and raising it above the level of the trunk for a few hours before the operation. This proceeding is especially useful in cases of large and vascular tumours.

2 United States Report on Amputations at the Hip-Joint. Circular No. 7.

3 Amputation at the Hip-Joint. By J. Sampson Gamgee.

vOL. $\mathrm{xV}$. - NO. $\mathrm{x}$. 